\title{
Correspondence between the large volcanic eruptions and ENSO events over AD 1525-2000
}

\author{
FANG Xiuqi ${ }^{1,2}$, ZHENG Xue $^{1}$, ZHANG Xing $^{1}$ \\ 1. Faculty of Geographical Science, Beijing Normal University, Beijing 100875, China; \\ 2. Key Laboratory of Environmental Change and Natural Disaster, Ministry of Education, Beijing Normal Uni- \\ versity, Beijing 100875, China
}

\begin{abstract}
ENSO is an interannual mode which may be affected by external forcing, such as volcanic eruptions. Based on the reconstructed volcanic eruptions chronology and ENSO sequences, both 195 large volcanic eruptions (VEI $\geqslant 4$ ) and 398 ENSO (EI Niño and La Niña) events were extracted from 1525 to 2000. An analysis of the correspondence between the large volcanic eruptions and ENSO events was performed by matching the large volcanic eruptions with the types and magnitudes of ENSO events present in the 0-2 years after the eruptions. The results show the following: (1) The percentages of ENSO events within the 3 years after the large eruptions had increased to $68.3 \%$ from $31.7 \%$ compared with those with no-eruptions in the previous 0-2 years. In addition, the ratio of El Niño to La Niña events turned from 2:3 to 1:1, and more El Niño events occurred in the 0 year after eruptions in the low-latitudes of the Northern Hemisphere and in the tropics but more La Niña events occurred in the 0 year after in the high-latitudes of the Northern Hemisphere and the Southern Hemisphere. (2) After the eruptions, the weak (W) El Niño events had increased by 8 percentage points and the very strong (VS) El Niño events had decreased by 10 percentage points; conversely, there was a decrease by 15 percentage points of the weak La Niña events and an increase by 11.4 percentage points of the very strong La Niña events. Specifically, the percentages of strong La Niña events increased to a peak at $1(+1)$ year after the eruptions. (3) The percentage of eruptions followed by single-year ENSO was the greatest. The percentage of ENSO events that occurred in the consecutive 2 years following an eruption was approximately equal to the percentage of events that occurred consecutively 3 years following an eruption, and both sets of ENSO magnitudes showed a decreasing trend.
\end{abstract}

Keywords: ENSO; large volcanic eruptions (VEI $\geqslant 4)$; regional volcanoes; relationship

\section{Introduction}

Both volcanic eruptions and the El Niño-Southern Oscillation (ENSO) could lead to global climatic anomalies with worldwide impacts (Collins et al., 2010; Harshvardhan, 1979; Rampino and Self, 1984; Robock et al., 1995; Timmreck, 2012). For example, the 1815 eruption of Tambora caused the "year without a summer" in 1816 in Europe where the cold and wet summer had a devastating

Received: 2018-12-19 Accepted: 2019-04-23

Foundation: National Natural Science Foundation of China, No.41430528

Author: Fang Xiuqi (1962-), Professor, specialized in the research of environmental change. E-mail: xfang@bnu.edu.cn 
effect both economically and socially (Stomme and Stommel, 2010); the severe drought in many parts of the world during 1877-1878 for the ENSO anomaly induced vast famine and death (Mishra et al., 2019; Damodaran et al., 2018; Davis, 2002), of which more than 10 million people died in North China (Hao et al., 2010). Whether or not ENSO as an interannual mode could be affected by external forcing, such as volcanic eruptions, is of the utmost importance for better understanding not only the extreme climate events but also their impacts on humans and society (King et al., 2016; Zebiak et al., 2015; Dilley and Heyman, 1995).

Handler (1984) first reported that low-latitude explosive volcanic eruptions increase the probability of El Niño events based on reconstructed historical volcanoes and SST (sea surface temperature) data from 1866 to 1982 . However, the study was questioned due to its lack of statistical robustness, and the relationship between volcanic eruptions and ENSO has been a subject of active research since then (Adams et al., 2003; Clement et al., 1996; D'Arrigo et al., 2009; Emile-Geay et al., 2008; Handler, 1984; Khodri et al., 2017; Liu et al., 2017; Macher et al., 2015; Mann et al., 2005; McGraw et al., 2016; Mcgregor et al., 2010; McGregor and Timmermann, 2011; Ohba et al., 2013; Pausata et al., 2016; Predybaylo et al., 2017; Zhang et al., 2013). A number of studies have documented that volcanic forcing exerts a relatively weak but discernible influence on ENSO. However, there is no consensus on how volcanic eruptions impact ENSO emergence and phase up until now, that is, some studies show El Niño-like anomalies (Adams et al., 2003; Maher et al., 2015; Mann et al., 2005; Ohba et al., 2013), while others show La Niña-like anomalies (McGregor and Timmermann, 2011).

Climate model simulation is one of the primary methodologies for exploring the impact of volcanic eruptions on ENSO. However, the discrepancies in the mechanisms of the impacts of volcanic eruptions on ENSO still exist among different simulated results. Some of the results concerning how ENSO responds to volcanic forcings are controversial or even present contradictions. Mann et al. (2005) and Ohba et al. (2013) proposed the likelihood of an El Niño anomaly response to volcanic eruptions based on Zebiak-Cane and CGCM models. Mann's theory relied on the well-known hypothesis of the dynamical thermostat mechanism (Cement et al., 1996), which demonstrated that the incorporation of both the moderate upwelling of subsurface water in the eastern equatorial Pacific and the reduced oceanic vertical temperature gradient acts to weaken volcanic cooling in the nearby region. The resultant positive zonal gradient of SST initiates El Niño, and this effect is eventually amplified by the Bjerknes feedback (Bjerknes, 1969). In addition, Khodri et al. (2017) presented the El Niño events that appeared within the 2 years following tropical volcanic eruptions using a simulation from the CMIP5 model. However, their preferred impact hypothesis differs from that previously mentioned. Khodri et al. (2017) stated that volcanically induced cooling in tropical Africa weakens the West African monsoon, and the resulting atmospheric Kelvin wave drives equatorial westerly wind anomalies over the western Pacific. Subsequently, the air-sea interactions in the Pacific amplify this wind anomaly, favoring an El Niño-like response. Conversely, McGregor and Timmermann (2011), using the Community Climate System Model (CCSM3), found that there should be a La Niña event instead of an El Niño after tropical volcanic eruptions and that these events peaked around the time the volcanic forcing peaked. They proposed a hypothesis that states that the deeper mixed layers of the warm pool respond slowly to the cooling effects of volcanic eruptions than is observed in the eastern Pacific; then, the enhancement of the SST gradient in the equatorial Pacific results in a La Niña-like phenomenon. Pausata et al. (2015) suggested that El Niño occurred more easily during the first winter following a 
high-latitude volcanic eruption in the Northern Hemisphere, which they demonstrated via modeling. The magnitude of an El Niño event would vary with different feedback mechanisms and would depend on the ENSO-related initial conditions when the volcano erupted. Liu et al. (2018b) found that volcanic eruptions impact on ENSO depending on both eruption type and initial ocean condition (IOC) by combining last-millennium proxy reconstructions with simulation results. It is more likely that El Niño would mature in the first or second winter following Northern Hemispheric, tropical and Southern Hemispheric eruptions when IOC is not a strong El Niño, on opposite that there would be no significant El Niño in the first winter after any types of eruption in case of a strong El Niño-IOC.

To explore the facts more closely, more credible proof of the relationship between volcanoes and ENSO could be obtained by comparing and analyzing the historically occurring volcanic eruptions and ENSO events. Relevant research has been increasingly focused on improving the reconstructions of volcanic eruptions and ENSO since Handler (1984) proposed that the probability of an ENSO event would increase after low-latitude volcanic eruptions. Adams et al. (2003) suggested roughly a doubling of the probability of an ENSO event in the first summer following a tropical volcanic eruption using the reconstructed volcanic records and ENSO sequence from 1649 to 2000. Mcgregor et al. (2010) made a subset of the unified ENSO proxy (UEP) data for each of the recorded volcanic events of the past 300 years, consisting of the 2 years prior to the volcanic event, the event year and the 5 years following the event. Then, they found that the probability of an El Niño event increased by approximately $40 \%$ in the year of a volcanic event and that the probability of a La Niña event increased by approximately $30 \%$ in the 3 years after a volcanic event. Based on the reconstructed ENSO and multi-latitude explosive volcanism datasets from the past millennium, Liu et al. (2018a) presented an El Niño-like event that was easily triggered after Northern Hemispheric and tropical volcanic eruptions, whereas a La Niña-like event was found to respond to the Southern Hemispheric eruptions.

This work aims to show the relationship between ENSO and volcanic events using additional facts and perspectives. Specifically, this study based on the reconstructed volcanic and ENSO sequences from 1525 to 2000 manufactured multidimensional groups of volcanic eruption events and varied ENSO types, magnitudes, amounts and so on. Furthermore, we conducted a statistical analysis of each matched group to determine the impact of volcanic eruptions on ENSO events.

\section{Data and methods}

\subsection{Data sources}

The volcanic sequence was taken from the open access Volcanic Eruption Chronology, consisting of 1449 events since the Holocene and reconstructed by Smithsonian Institution Global Volcanic Project of the United States (http://volcano.si.edu/). This chronology includes the name, location, altitude, Volcanic Eruption Index (VEI), and time (starting, ending and duration) of these events. The VEI is regarded as the most effective reference for describing historical explosive volcanism, whose magnitudes can be estimated on a scale from 0 to 8 (Newhall and Self, 1982). Among the volcanic eruptions, those with VEI equal to or greater than 4 could eject large amounts of various gases and particulate matter (ash) into the stratosphere, resulting in vast impacts on the global climate. Hence, volcanic eruptions with VEI $\geqslant 4$ are defined as Large Volcanic Eruptions (Newhall and Self,1982; Hao et al., 2014). 
The ENSO dataset was derived from the chronology of ENSO events from 1525 to 2000 produced by Gergis and Fowler (2009) and based on 15 sequences of tree rings, coral reefs, ice cores, historical achieves, etc. This chronology not only incorporates ENSO event types but also includes a criteria indicator of the Quality adjusted Magnitude (MQ) to classify the magnitude of ENSO (El Niño /La Niña) events. According to the MQ score, a higher score corresponds to a stronger rank, and all ENSO events were divided into five grades: extreme (E), very strong (VS), strong (S), moderate (M), and weak (W) (Gergis and Fowler, 2009). Five event classes ranging from extreme ( $>90$ th percentile), very strong (70th-90th percentile), strong (50th-70th percentile), moderate (50th-30th percentile) to weak events $(<30$ th percentile) were identified from the instrumental period and the definition of an extreme event is consistent with that used by Working Group 1 of the Intergovernmental Panel on Climate Change (IPCC) (IPCC, 2013; Trenberth et al., 2007).

\subsection{Methods}

195 large volcanic eruptions (VEI $\geqslant 4$ ) were extracted from between 1525-2000 from the Volcanic Eruption Chronology (Siebert et al., 2011). If more than one volcano erupted with different magnitudes in a year, the largest VEI was selected as the eruption of the year. If a volcanic eruption lasted for several years, the year with the maximum eruption was regarded as the eruption year for the volcano. If the maximum eruption could not be identified, the year of the start of the eruption was regarded as the eruption year (Figure 1).

The ENSO events during 1525-2000 were classified as one of two types, El Niño or La Niña, within each year. If both El Niño event (El) and La Niña event (La) signals existed in the same year in the above compiled ENSO chronology given by Gergis and Fowler (Gergis and Fowler, 2009), the event with the greater magnitude (i.e., extreme $>$ very strong $>$ strong $>$ moderate $>$ weak) was selected as the type for that year. If the magnitudes of the El Niño event and La Niña event were the same in one year, the event type with the higher MQ score was selected (Gergis and Fowler, 2009). Ultimately, 398 years of ENSO events were obtained (Figure 1).

To analyze the features of the types and amounts of ENSO events in the years following the large volcanic eruptions (VEI $\geqslant 4$ ), the selected large volcanic eruptions and ENSO events were matched year by year from 1525 to 2000. Generally, hemispheric or global cooling effects caused by a large volcanic eruption could last at least 1-2 years (Ding et al., 2014; Dutton and Christy, 1992; Hegerl, 2003; Robock and Mao, 1995; Stenchikov et al., 2009; Thompson et al., 2009; Timmreck, 2012; Yamamoto et al., 1975). Hence, it was selected into this study that the ENSO events of both event types (i.e., El Niño or La Niña) occurred $0,1(+1)$ and 2(+2) years after large volcanic eruptions. Within the prior 0-2 years of their occurrence, the ENSO event and its type (El Niño or La Niña) were distinguished as either the one there was no eruption or the one there was eruption. If there were more than one large volcanic eruption in the $0-2$ years preceding an ENSO event, the volcano with the highest VEI was selected as the match for the ENSO event. If there were same magnitudes of large volcanic eruptions both in the 1 and 2 years before an ENSO event, the ENSO event was matched with the eruption in the 1 year before.

The impacts of volcanic eruptions on ENSO events depend on the atmospheric circulation and the dispersion path and distribution of volcanic ejected materials (Zhang et al., 1994; Stevenson et al., 2016). To understand the variety of the impacts of volcanic eruptions on ENSO events in different regions, the global volcanic eruptions were classified into four latitude zones according to where those eruptions located in this study, including equatorial $\left(15^{\circ} \mathrm{N}-15^{\circ} \mathrm{S}\right)$, the low-middle lati- 

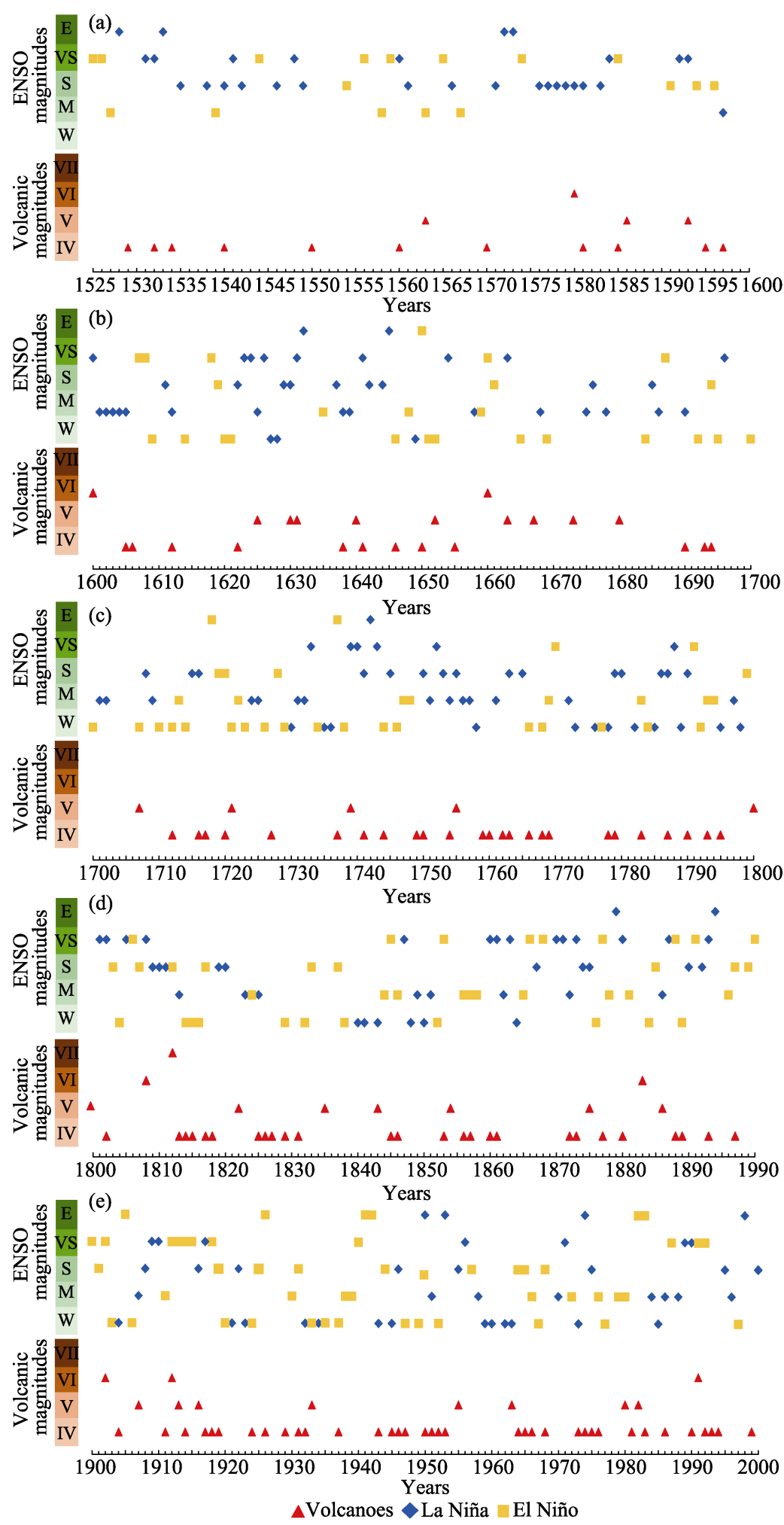

Figure 1 The chronology of different magnitudes of large volcanic eruptions (Siebert et al., 2011) and El Niño/La Niña events (Gergis and Fowler, 2009) from 1525 to 2000 
tudes of the Northern Hemisphere $\left(15^{\circ} \mathrm{N}-50^{\circ} \mathrm{N}\right)$, the high latitudes of the Northern Hemisphere (north of $50^{\circ} \mathrm{N}$ ), and the Southern Hemisphere (south of $15^{\circ} \mathrm{S}$ ). Each eruption was matched the ENSO events based on the volcanic regions. Due to the low latitude volcanic eruption having a faster impact on the tropical ocean-air system (Dutton and Christy, 1992; Khodri et al., 2017; Robock, 2000; Stenchikov et al., 2004), a low-latitude eruption in an ENSO year was selected when more than one eruption with the same magnitude occurred in different regions. Otherwise, eruption events located at high latitudes occurring 1-2 years prior to an ENSO event were selected.

The amounts, types, and magnitudes of ENSO events occurring within the $0-2$ years after large eruptions were accounted for annually to obtain a better understanding of the proceeding and inner mechanisms of the ENSO response to large volcanic eruptions.

Both z-test and t-test are widely used method for the significance testing. Under the premise of unifying the corresponding distribution pattern, $z$-test is usually used for large samples $(\geqslant 30)$, while t-test is used for small samples $(\leqslant 30)$. In this study, a z-test was used foe the significance testing between ENSO events amounts following large eruptions and those with no eruptions in the $3(0-2)$ years preceding their occurrence; a t-test was used for the significance testing between each of the five magnitudes of ENSO events within the 3 years following an eruption and those that without a preceding eruption. The significance level was $\alpha=0.05$ (Sheng, 2008).

\section{Results}

\subsection{Impacts of large eruptions (VEI $\geqslant 4)$ on the types and amounts of ENSO events}

3.1.1 Difference in the amounts of ENSO events within the 0-2 years with and without a large eruption

The probability of ENSO events occurring within the 3 (0-2) years following a large volcanic eruption more likely increased relative to periods without a large volcanic eruption. In 1525-2000, there were a total of 195 large volcanic eruptions, and 398 years with ENSO events. Of the years with ENSO events, there were 272 years, accounting for $68.3 \%$ of the total, fell within the range of 3 years after a large eruption; another 126 ENSO events occurred without a large eruption occurring within the 3 years prior to these ENSO events, accounting for $31.7 \%$ of the total. That is, the ENSO events occurring within 3 years following a large eruption are more common than those without eruptions in the previous $0-2$ years by 36.6 percentage points (Table 1). The differences between ENSO events following large eruptions and those with no eruptions in the $0-2$ years preceding their occurrence pass the $95 \%$ significant level by z-test $(\alpha<0.05)$.

Table 1 Amounts and percentage of ENSO events occurring in the two scenarios with and without large eruptions during 1525-2000

\begin{tabular}{lccc}
\hline \multicolumn{1}{c}{ Volcanic eruption } & El Niño & La Niña & ENSO \\
\hline No-eruption (in the prior 0-2 years) & $51(40.5 \%)$ & $75(59.5 \%)$ & $126(31.7 \%)$ \\
Eruptions (in the prior 0-2 years) & $137(50.4 \%)$ & $135(49.6 \%)$ & $272(68.3 \%)$ \\
Total & $188(47.2 \%)$ & $210(52.8 \%)$ & $398(100 \%)$ \\
No-eruptions\%: Eruptions\% & $27.1: 72.9$ & $35.7: 64.3$ & $31.7: 68.3$ \\
\hline
\end{tabular}


There was a high probability of ENSO events occurring in the same year with a large volcanic eruption. Of the 272 ENSO events that occurred after large volcanic eruptions, $47.8 \%$ were within the same year as with the large volcanic eruptions, $29.4 \%$ were within the next $(+1)$ year and $22.8 \%$ were within the next +2 year (Figure $2 a$ ).
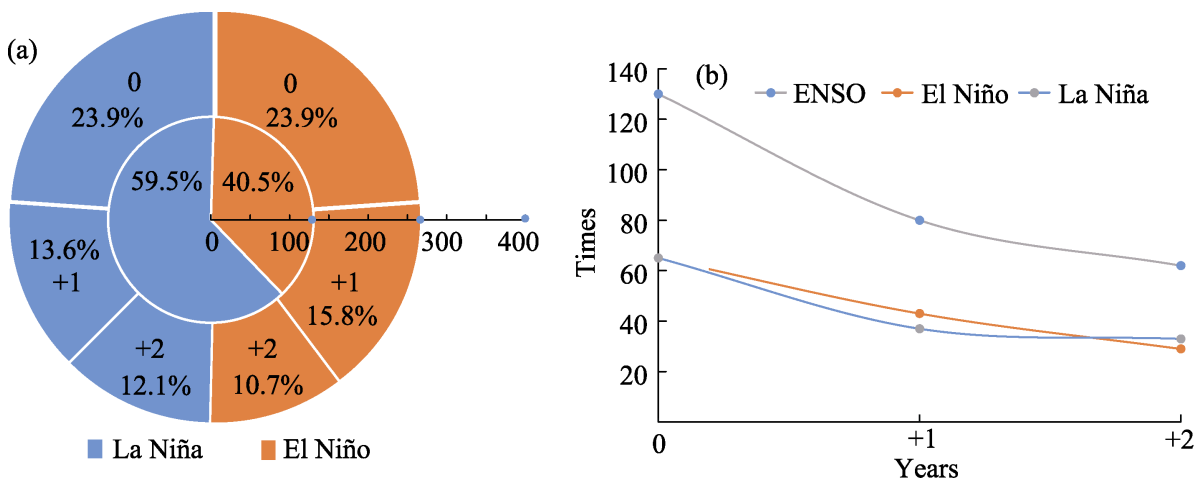

Figure 2 ENSO events occurred in $0,+1,+2$ years after large volcanic eruptions from 1525 to 2000 in global extent (a. percentage of ENSO events within 0-2 years of no-eruptions (inner ring) and eruptions (outer ring), respectively. b. years of El Niño, La Niña and all ENSO in $0,+1$, and +2 years after an eruption)

\subsubsection{Difference in the ratio of El Niño to La Niña events after large volcanic eruptions}

The proportion of El Niño years increased significantly following large volcanic eruptions. Of the 126 ENSO events without large volcanic eruptions occurring in the prior 0-2 years, the ratio of El Niño to La Niña events was approximately 2:3. Of the 272 ENSO events that occurred within 0-2 years after the large volcanic eruptions, the ratio of El Niño to La Niña events was approximately 1:1 (Figure 2a).

Both the numbers of El Niño and La Niña events decreased from 0 to 2 years after the large volcanic eruptions, as did ENSO events overall (Figure 2b). A total of 65 El Niño years and $65 \mathrm{La}$ Niña years occurred in the year with a large volcanic eruption; 43 El Niño years and 37 La Niña years occurred in the first year after a large volcanic eruption; 29 El Niño years and 33 La Niña years occurred in the second year after a large volcanic eruption.

3.1.3 Differences in the amounts and types of ENSO events following large volcanic eruptions occurring in different regions

There were no significant discrepancies in all of the regions between the percentages of eruptions and ENSO events occurred within 0-2 years after the eruptions during 1525 to 2000 . Of the 195 large eruptions and the 272 ENSO events following these eruptions within the 3 years during 1525-2000, 38.5\% eruptions and 36.8\% ENSO events occurred in the equatorial zone; $27.2 \%$ eruptions and $31.3 \%$ ENSO events occurred in the low-middle latitudes of the Northern Hemisphere; $25.6 \%$ eruptions and 26\% ENSO events occurred in the high latitudes of the Northern Hemisphere; while 8.7\% eruptions and 5.9\% ENSO events occurred in the Southern Hemisphere (Figure 3).

Differences existed among the percentage of those ENSO events occurring within the $0,+1$, and +2 years after the large volcanic eruptions in the four regions, although the percentage was the largest in the year of the eruption in all regions and globally. In the equatorial zone, $52 \%$ of ENSO events occurred in the year of the eruption. In the low-middle latitudes of the Northern Hemisphere 


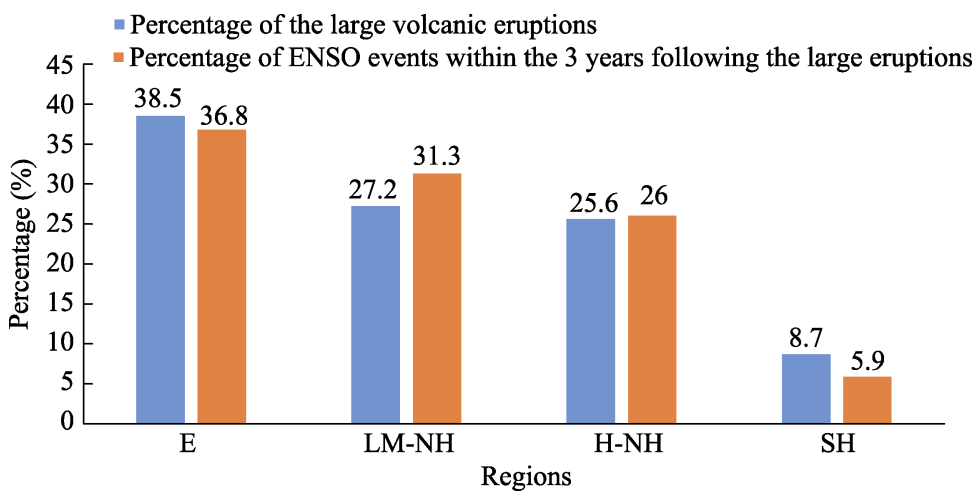

Figure 3 Percentages of large volcanic eruptions and ENSO events occurring within the 0-2 years following the large eruptions in the four regions of the Equator (E), the Low-Middle Latitudes of the Northern Hemisphere (LM-NH), the High Latitudes of the Northern Hemisphere (H-NH) and the Southern Hemisphere (SH)

$\left(15^{\circ} \mathrm{N}-50^{\circ} \mathrm{N}\right)$, only $43.5 \%$ of ENSO events occurred in the year of the eruption. For the high latitudes of the Northern Hemisphere (north of $50^{\circ} \mathrm{N}$ ), $48 \%$ of ENSO events occurred in the year of the eruption that was much closer to the $47.8 \%$ accounted globally in the 0 year of eruption, but the percentage of events occurred in the +2 year was slightly higher than that in the +1 year. In the Southern Hemisphere (south of $15^{\circ} \mathrm{S}$ ), the percentage of ENSO events occurred in the +1 year of the eruption was much higher than the $29.4 \%$ accounted globally in the +1 year after the eruption, but those occurred in the 0 and +2 years were lower than the $47.8 \%$ and $22.8 \%$ accounted globally in the 0 year and +2 year after the eruption, respectively (Figure 4 ).

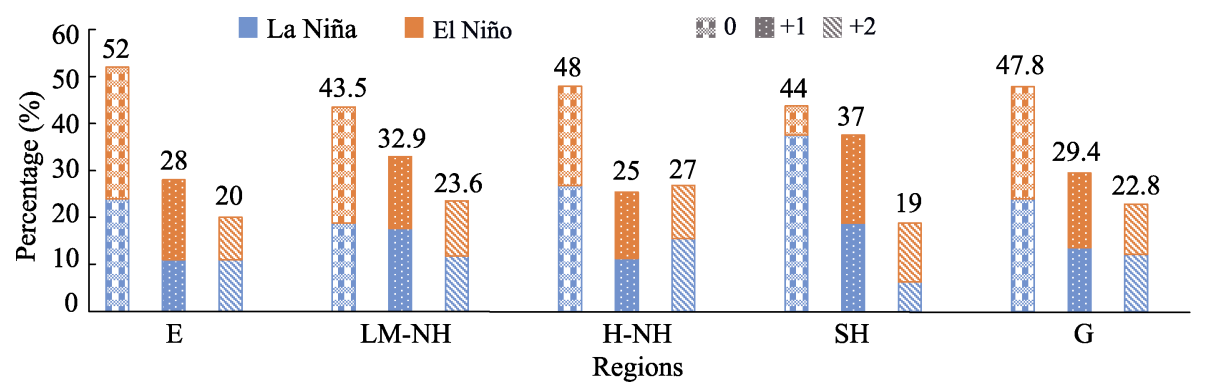

Figure 4 Percentages of ENSO events occurring in $0,+1$ and +2 years after large volcanic eruptions in different regions and at global extent: the Equator (E), the Low-Middle Latitudes of the Northern Hemisphere (LM-NH), the High Latitudes of the Northern Hemisphere (H-NH), the Southern Hemisphere (SH) and Globe(G). Each column was divided into El Niño and La Niña events

Differences were also found in the ratios of La Niña to El Niño events occurred within the 3 years after a large volcanic eruption in the four regions. In the equatorial and low-latitudes Northern Hemisphere zones, La Niña events occurred less often than El Niño events, with ratios of 0.85:1 and $0.93: 1$ in the $0-2$ years and $0.86: 1$ and $0.76: 1$ in the 0 year, respectively. In contrast, the number of La Niña events exceeded those of El Niño events in the Northern Hemisphere's high latitudes and the Southern Hemisphere, where the ratios were 1.15:1 and 1.67:1 in the 0-2 years and 1.27:1 and 6:1 in the 0 year, respectively (Figure 4).

\subsection{Impacts of large eruptions (VEI $\geqslant 4)$ on the magnitudes of ENSO events}

3.2.1 Differences in magnitudes of ENSO events within 0-2 years with and without a large eruption

There was significant difference by t-test between the percentages of ENSO events in various mag- 
nitudes occurring in the +1 and +2 years following the eruptions and those without a preceding eruption on the significance level of 0.05 and 0.01 , respectively. Within $0-2$ years after volcanic eruptions, both the percentage of the weak and strong ENSO events showed a downward trend, whereas, the others including the moderate, very strong and extreme ENSO events respectively presented an upward trend than that with no eruptions (Figure 5a).
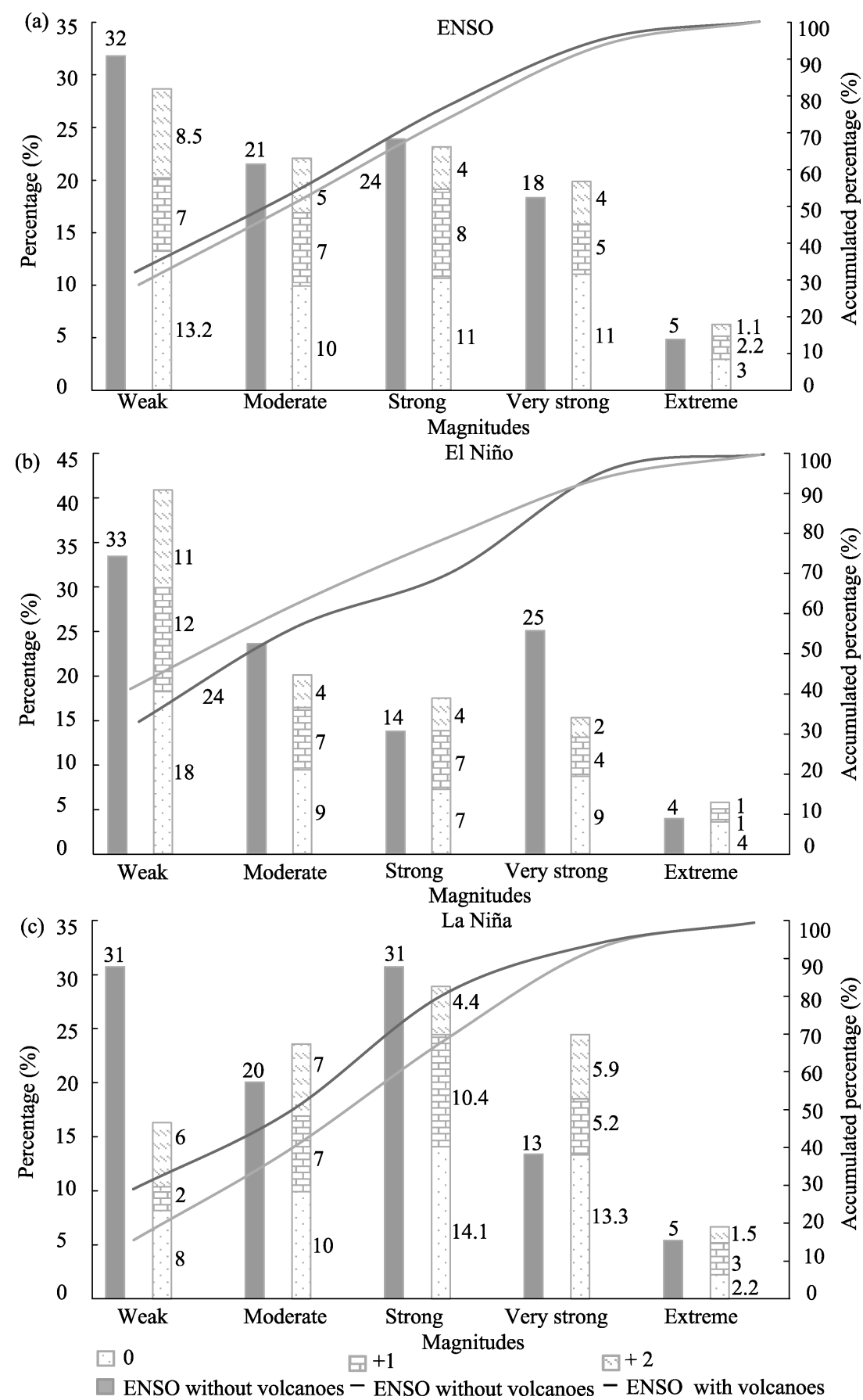

Figure 5 Percentages and accumulative percentages of various magnitudes of ENSO events within the following $0-2$ years of no-eruptions and eruptions (a. ENSO, b. El Niño, c. La Niña) 
Either El Niño or La Niña, the difference between the percentages of various magnitude events occurring in the +1 and +2 years after large eruptions and no eruptions before that passed the significant level of $\alpha=0.05$. For the El Niño events that occurred within the $0-2$ years following an eruption, the weak El Niño events were more by 8 percentage points and the very strong El Niño events were less by 10 percentage points than that with no eruptions. As to the La Niña events, it was relatively distinct that the weak La Niña events were less by 15 percentage points and the very strong events were more by 11.4 percentage points than that no eruptions (Figure 5).

3.2.2 Differences in the magnitudes of El Niño events among the 0-2 years following large volcanic eruptions

The weak El Niño events were more common than other types in each year of 0-2 years after a large volcanic eruption, which totally accounted for $41 \%$ of the post-eruption El Niño events (Figure $5 b$ ). The weak El Niño events occurred in the 0 year, the +1 year, and the +2 year after the eruptions accounted for $38.5 \%, 37 \%$, and $51.7 \%$ of the total El Niño events in the same years, respectively. The moderate El Niño events occurred in the 0 year, the +1 year, and the +2 year accounted for $20 \%, 23 \%$ and $17.2 \%$ of the total in the same years. The strong El Niño events occurred in the 0 year, the +1 year, and the +2 year accounted for $15 \%, 21 \%$ and $17.2 \%$ of the total in the same years. $18.5 \%$ of the total very strong El Niño events and $8 \%$ of the total extreme El Niño events occurred in the eruption years.

3.2.3 Differences in magnitudes of La Niña events within 0-2 years following large volcanic eruptions

The strong La Niña events were more common than the other magnitude types in the 0 year and +1 year, and the strong La Niña events had a largest increase from the 0 year to the +1 year after volcanic eruptions. While the moderate La Niña events were more common in the +2 year (Figure $5 \mathrm{c}$ ).

The weak La Niña events occurred in the 0 year, the +1 year, and the +2 year after the eruptions accounted for $17 \%, 8.1 \%$, and $24.2 \%$ of the total La Niña events in the same years, respectively. The moderate La Niña events occurred in the 0 year, the +1 year, and the +2 year accounted for $21.5 \%, 24 \%$ and $27.3 \%$ of the total in the same years, respectively. The strong La Niña events occurred in the 0 year, the +1 year, and the +2 year accounted for $29.2 \%, 38 \%$ and $18.2 \%$ of the total in the same years, respectively. The very strong La Niña events occurred in the 0 year, the +1 year, and the +2 year accounted for $27.7 \%, 18.9 \%$, and $24.2 \%$ of the total in the same years, respectively. The extreme La Niña events occurred in the 0 year, the +1 year, and the +2 year after the eruptions accounted for $4.6 \%, 11 \%$ and $6.1 \%$ of the total La Niña events in the same years.

3.2.4 Differences in magnitudes of ENSO events after large volcanic eruptions in different regions

There were regional differences in the probability distributions of the magnitudes of El Niño and La Niña events occurring within the $0-2$ years after a large volcanic eruption.

More weaker El Niño events and more stronger La Niña events tended to occur after large volcanic eruptions in all zones. However, the ratios of the El Niño events to the La Niña events of different magnitudes varied significantly from zone to zone. For the 100 ENSO events in the equatorial zone, the ratio of El Niño to La Niña events was 1:0.85. The ratio of the weak El Niño events to the weak La Niña events was 1:0.41, and the ratio of the very strong El Niño events to the very strong La Niña events was 1:3 (Figure 6a). 
Of the 85 ENSO events in the low-middle latitudes of the Northern Hemisphere, the ratio of El Niño to La Niña events was 1:0.93. Meanwhile, the ratios of weak and moderate El Niño events to the same magnitudes of La Niña events were 1:0.5 and 1:0.46, respectively. The ratios of strong and extreme El Niño events to the same magnitudes of La Niña events were 1:3.5 and 1:3, respectively (Figure 6b).

(a)

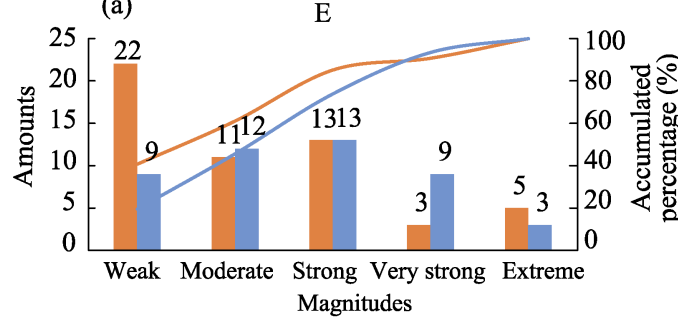

(c)

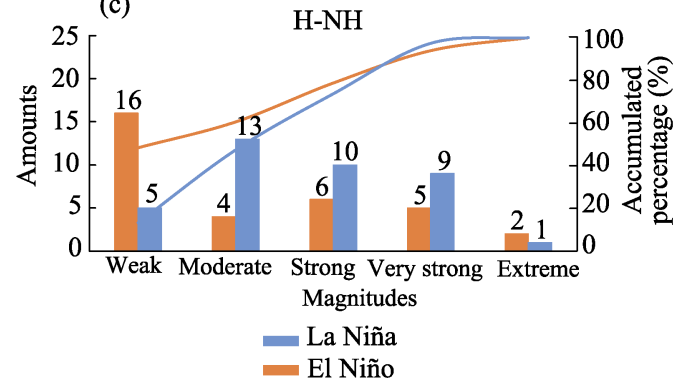

(b)

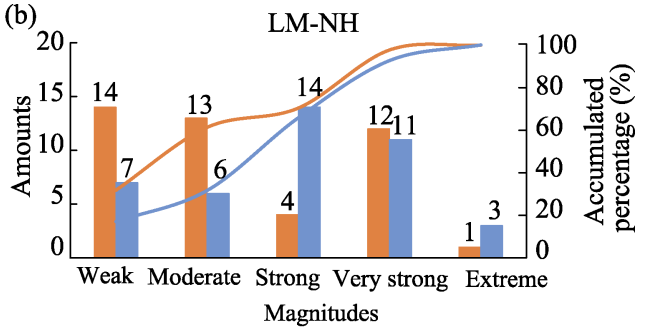

(d)

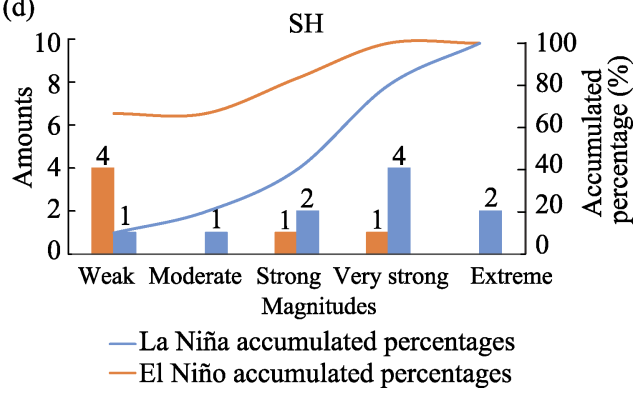

Figure 6 The numbers and accumulative percentages of various magnitudes of ENSO events occurred within the 0-2 years after a large volcanic eruption in four regions: (a) The Equator (E), (b) the low-middle latitudes of the Northern Hemisphere (LM-NH), (c) the high latitudes of the Northern Hemisphere (H-NH), and (d) the Southern Hemisphere (SH)

In the high latitudes of the Northern Hemisphere, there were 71 ENSO events and a ratio of 1:1.15 of El Niño to La Niña events. The ratios of weak and extreme El Niño events to the same magnitudes of La Niña events were 1:0.31 and 1:0.5, respectively. In addition, the ratios of the moderate, strong and very strong El Niño events to the same magnitudes of La Niña events were 1:3.25, 1:1.67 and 1:1.8, respectively (Figure 6c).

In the Southern Hemisphere, among the 16 ENSO events occurring after large volcanic eruptions, 4 were weak El Niño events, 4 were very strong La Niña events and 2 were extreme La Niña events (Figure 6d).

\subsection{Impacts of large eruptions on the temporal distribution of ENSO events}

Among the 195 volcanic eruptions during 1525 to $2000,41 \%$ of eruptions were followed by 1 ENSO event, with $35.1 \%, 3.7 \%$ and $2.2 \%$ occurring in the $0,+1$, and +2 year after an eruption, respectively (Figure 7a). A total of $26.9 \%$ eruptions were followed by 2 consecutive ENSO events following the eruptions, with $19.4 \%$ and $7.5 \%$ started from the 0 and +1 year, respectively (Figure 7a). Of the 2 consecutive ENSO events, $73.5 \%$ were the same type while the other $26.5 \%$ switched types between El Niño and La Niña. 9\% of the eruptions were followed by 2 inconsecutive ENSO events that occurred in the 0 year and the +2 year, with $2 / 3$ of those maintaining the same ENSO type in both years (Figure 7a). Overall, 23.1\% 
of eruptions were followed by 3 ENSO events occurred consecutively in the $0-2$ years after the eruptions with a ratio of 4:6 for those of the same ENSO type and those with different ENSO types (Figure 7a).

Among the ENSO events that occurred in the 2 consecutive years following large volcanic eruptions, $44 \%, 31 \%$ and $25 \%$ showed that the magnitude decreased, enhanced and unchanged in the second year, respectively (Figure 7b). Of the ENSO events that occurred in the 0 year and reappeared in the +2 year, the ratios of the magnitudes increased, decreased and remained stable were 4:3:2 (Figure 7c). Among the ENSO events that occurred in the 3 consecutive years after an eruption, $65 \%$ tended to decrease in magnitudes from 0 to 2 years, including weakening, enhancing first and then weakening or weakening first and then remaining unchanged; $32 \%$ tended to increase in magnitudes from the 0 year to the 2 years, including strengthening or strengthening first and then remaining unchanged; $3 \%$ remained at the same magnitude throughout (Figure $7 \mathrm{~d}$ ).

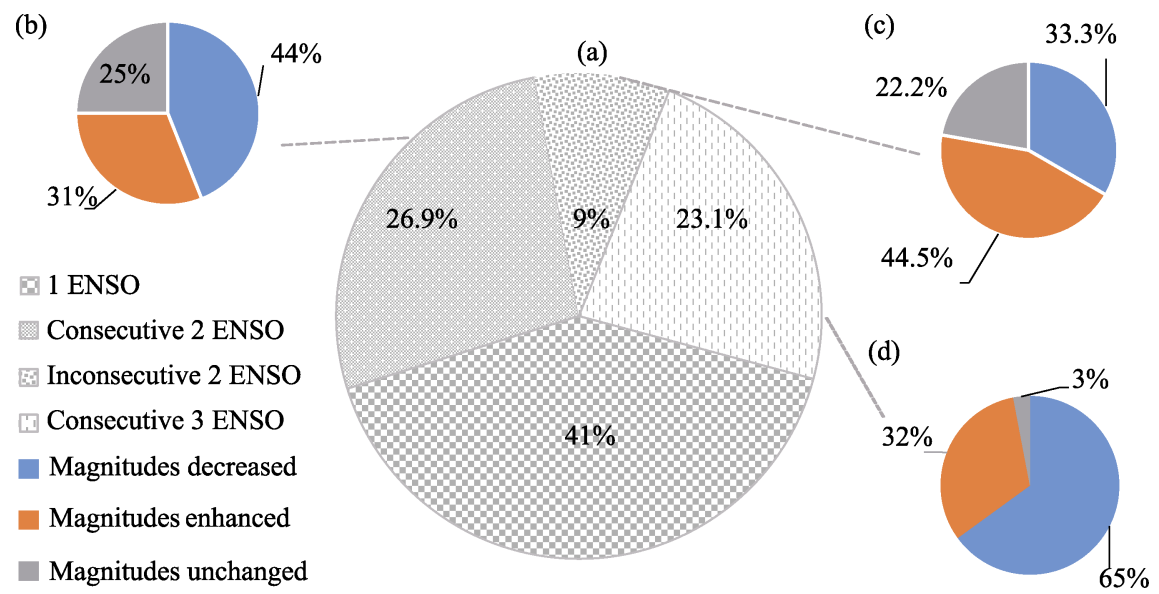

Figure 7 The continuity of the ENSO events and the magnitudes within 0-2 years after volcanic eruptions ((a) The percentages of volcanic eruptions followed by different amounts of ENSO events (1, 2 or 3 events) within the 3 years; (b) the percentages of the 2 consecutive ENSO events with different trend in magnitude; (c) the proportions of the 2 inconsecutive ENSO events with different trends in magnitude; (d) the proportions of the 3 consecutive ENSO events with different trends in magnitude)

\section{Discussion}

It was first pointed out by Handler (1984) that ENSO as an interannual mode of climate system could be affected by volcanic eruptions. He proposed that the probability of an El Niño-like event would increase after low-latitude volcanic eruptions based on the historical volcanic eruptions and SST data from 1866 to 1982 (Handler, 1984). More later researches based on longer series of proxy reconstruction supported that ENSO could be affected by volcanic eruptions (Adams et al., 2003; Mcgregor et al., 2010; Liu et al., 2018a). Agreeing with the above viewpoint, the results of this paper, based on the reconstructed series of 1525-2000, show that 36.6 percentage points more ENSO events occurred within the 0-2 years after a large volcanic eruption than that without an eruption. The result of this paper also shows more El Niño-like events after large volcanic eruptions that the ratio of El Niño 
to La Niña events changed to 1:1 after the large volcanic eruptions in contrast to 2:3 without large volcanic eruptions.

The results of this paper show the low-latitudes of Northern Hemisphere and tropical volcanic eruptions might easily trigger an El Niño-like event, whereas a La Niña-like event was found to respond to the Southern Hemisphere eruptions. It agrees with the previous studies both based on proxy-based reconstructions and modeling (Stevenson et al., 2016; Liu et al., 2018a).

\section{Conclusions}

Both volcanic eruptions and the El Niño-Southern Oscillation (ENSO) could lead to global climatic anomalies with worldwide impacts. Study on the relationship between volcanic eruption and ENSO is of importance for better understanding how they interact in driving global or regional extreme climate events.

By matching the 195 large volcanic eruptions $(V E I \geqslant 4)$ with the types and magnitudes of 398 ENSO events present in the 0-2 years after the eruptions occurred from 1525 to 2000, an analysis of the correspondence between the large volcanic eruptions and ENSO events was performed. The results show that the large volcanic eruptions could affect the occurrence of ENSO events in multi-aspects as follows:

(1) In 1525-2000, the ENSO events that occurred within the 0-2 years after a large volcanic eruption $(\mathrm{VEI} \geqslant 4)$ were greater than that without an eruption by 36.6 percentage points; the ratio of El Niño to La Niña events changed from $2: 3$ to $1: 1$; the number of ENSO events following eruptions was the greatest $(47.8 \%)$ in the 0 year rather than in the +1 year $(29.4 \%)$ or in the +2 year $(22.8 \%)$.

(2) There were more El Niño events than La Niña events occurred in the 0 year after the eruptions in the regions of equator and Northern Hemisphere's low-middle latitudes; but more La Niña events in the 0 year after the eruptions in the high-latitudes of the Northern Hemisphere and the Southern Hemisphere.

(3) Weak El Niño events occurred more often than all other types in all of the 0-2 years after a large volcanic eruption. While strong La Niña events occurred more than other types in the 0 year and +1 year following the volcanic eruptions; moderate La Niña events were more common in the +2 year.

(4) Some $41 \%$ of the large eruptions were followed by 1 ENSO event. $26.9 \%$ and $23.1 \%$ of the eruptions were followed by 2 or 3 consecutive ENSO events, respectively. In both cases of the 2 and 3 consecutive ENSO events, the ENSO magnitudes were dominated by a decreasing trend.

\section{References}

Adams J B, Mann M E, Ammann C M, 2003. Proxy evidence for an El Niño-like response to volcanic forcing. Nature, 426(6964): 274-278.

Briffa K R, Jones P D, Schweingruber F H et al., 1998. Influence of volcanic eruptions on Northern Hemisphere summer temperature over the past 600 years. Nature, 393(6684): 450-455.

Bjerknes J, 1969. Atmospheric teleconnections from the equatorial Pacific. Monthly Weather Review, 97(3): $163-172$.

Cheng D, Cui Y, Su F et al., 2018. The characteristics of the Mocoa compound disaster event, Colombia. Land- 
slides, 15(6): 1223-1232.

Clement A C, Seager R, Cane M A et al., 1996. An ocean dynamical thermostat. Journal of Climate, 9(9): 2190-2196.

Collins M, An S I, Cai W et al., 2010. The impact of global warming on the tropical Pacific Ocean and El Niño. Nature Geoscience, 3(6): 391-397.

Damodaran V, Allan R, Ogilvie A E J et al., 2018. The 1780s: Global climate anomalies, floods, droughts, and famines. The Palgrave Handbook of Climate History. London: Palgrave Macmillan Press.

Davis M, 2001. Late Victorian Holocausts: El Niño Famines and the Making of the Third World. London: Verso Press.

D'Arrigo R, Wilson R, Tudhope A, 2009. The impact of volcanic forcing on tropical temperatures during the past four centuries. Nature Geoscience, 2(1): 51-56.

Deng X Z, Huang J K, Qiao F B et al., 2010. Impacts of El Niño-Southern Oscillation events on China's rice production. Journal of Geographical Sciences, 20(1): 3-16.

Deser C, Alexander M A, Xie S P et al., 2010. Sea surface temperature variability: Patterns and mechanisms. Annual Review of Marine Science, 2(1): 115-143.

Dilley M, Heyman B N, 1995. ENSO and disaster: Droughts, floods and El Niño/Southern Oscillation warm events. Disasters, 19(3): 181-193.

Ding Y, Carton J A, Chepurin G A et al., 2014. Ocean response to volcanic eruptions in Coupled Model Intercomparison Project 5 simulations. Journal of Geophysical Research: Oceans, 119(9): 5622-5637.

Dutton E G, Christy J R, 1992. Solar radiative forcing at selected locations and evidence for global lower tropospheric cooling following the eruptions of El Chichón and Pinatubo. Geophysical Research Letters, 19(23): 2313-2316.

Emile-Geay J, Seager R, Cane M A et al., 2008. Volcanoes and ENSO over the past millennium. Journal of Climate, 21(13): 3134-3148.

Gergis J L, Fowler A M, 2009. A history of ENSO events since AD 1525: Implications for future climate change. Climatic Change, 92(3/4): 343-387.

Handler P, 1984. Possible association of stratospheric aerosols and El Niño type events. Geophysical Research Letters, 11(11): 1121-1124.

Handler P, 1986. Possible association between the climatic effects of stratospheric aerosols and sea surface temperatures in the eastern tropical Pacific Ocean. Journal of Climatology, 6(1): 31-41.

Hao Z, Wang H, Zheng J, 2014. Spatial and temporal distribution of large volcanic eruptions from 1750 to 2010. Journal of Geographical Sciences, 24(6): 1060-1068.

Hao Z X, Zheng J Y, Wu G F et al., 2010. 1876-1878 severe drought in North China: Facts, impacts and climatic background. Chinese Science Bulletin, 55(26): 3001-3007.

Harshvardhan M R, 1979. Perturbation of the zonal radiation balance by a stratospheric aerosol layer. Journal of the Atmosphere Sciences, 36(7): 1274-1285.

Hegerl G C, Crowley T J, Baum S K et al., 2003. Detection of volcanic, solar and greenhouse gas signals in paleo-reconstructions of Northern Hemispheric temperature. Geophysical Research Letters, 30(5): 1242. doi: 10.1029/2002GL016635.

IPCC, 2013. Climate Change 2013: The Physical Science Basis. Contribution of Working Group I to the Fifth Assessment Report of the Intergovernmental Panel on Climate Change. Cambridge and New York: Cambridge University Press.

Khodri M, Izumo T, Vialard J et al., 2017. Tropical explosive volcanic eruptions can trigger El Niño by cooling tropical Africa. Nature Communications, 8(1): 778. doi: 10.1038/s41467-017-00755-6.

King A D, van Oldenborgh G J, Karoly D J, 2016. Climate change and El Niño increase likelihood of Indonesian heat and drought. Bulletin of the American Meteorological Society, 97(12): S113-S117.

Lamb, H H, 1970. Volcanic dust in the atmosphere; with a chronology and assessment of its meteorological significance. Philosophical Transactions of the Royal Society of London. Series A, Mathematical and Physical Sciences, 266(1178): 425-533. 
Lehner F, Schurer A P, Hegerl G C et al., 2016. The importance of ENSO phase during volcanic eruptions for detection and attribution. Geophysical Research Letters, 43(6): 2851-2858.

Li J, Xie S P, Cook E R et al., 2013. El Niño modulations over the past seven centuries. Nature Climate Change, 3(9): 822-826.

Lim H G, Yeh S W, Kug J S et al., 2016. Threshold of the volcanic forcing that leads the El Niño-like warming in the last millennium: results from the ERIK simulation. Climate Dynamics, 46(11/12): 3725-3736.

Liu F, Li J, Wang B et al., 2018a. Divergent El Niño responses to volcanic eruptions at different latitudes over the past millennium. Climate Dynamics, 50(9/10): 3799-3812.

Liu F, Xing C, Sun L et al., 2018b. How do tropical, Northern Hemispheric, and Southern Hemispheric volcanic eruptions affect ENSO under different initial ocean conditions? Geophysical Research Letters, 45(23): 13,041-13,049.

Maher N, McGregor S, England M H et al., 2015. Effects of volcanism on tropical variability. Geophysical Research Letters, 42(14): 6024-6033.

Mann M E, Cane M A, Zebiak S E et al., 2005. Volcanic and solar forcing of the tropical Pacific over the past 1000 years. Journal of Climate, 18(3): 447-456.

Mass C, Schneider S H, 1977. Statistical evidence on the influence of sunspots and volcanic dust on long-term temperature records. Journal of the Atmospheric Sciences, 34(12): 1995-2004.

McGraw M C, Barnes E A, Deser C, 2016. Reconciling the observed and modeled Southern Hemisphere circulation response to volcanic eruptions. Geophysical Research Letters, 43(13): 7259-7266.

McGregor S, Timmermann A, 2011. The effect of explosive tropical volcanism on ENSO. Journal of Climate, 24(8): 2178-2191.

McGregor S, Timmermann A, Timm O, 2010. A unified proxy for ENSO and PDO variability since 1650 . Climate of the Past, 6(1): 1-17.

Meque A, Abiodun B J, 2015. Simulating the link between ENSO and summer drought in Southern Africa using regional climate models. Climate Dynamics, 44(7/8): 1881-1900.

Mishra V, Tiwari A D, Aadhar S et al., 2019. Drought and famine in India, 1870-2016. Geophysical Research Letters, 46(4): 2075-2083.

Newhall C G, Self S, 1982. The volcanic explosivity index (VEI): An estimate of explosive magnitude for historical volcanism. Journal of Geophysical Research: Oceans, 87(C2): 1231-1238.

Niemeier U, Timmreck C, Graf H F et al., 2009. Initial fate of fine ash and sulfur from large volcanic eruptions. Atmospheric Chemistry and Physics, 9(22): 9043-9057.

Ohba M, Shiogama H, Yokohata T et al., 2013. Impact of strong tropical volcanic eruptions on ENSO simulated in a coupled GCM. Journal of Climate, 26(14): 5169-5182.

Oliver R C, 1976. On the response of hemispheric mean temperature to stratospheric dust: An empirical approach. Journal of Applied Meteorology, 15(9): 933-950.

Oman L, Robock A, Stenchikov G et al., 2005. Climatic response to high-latitude volcanic eruptions. Journal of Geophysical Research: Atmospheres, 110(D13): D13103. doi: 10.1029/2004JD005487.

Pausata F S R, Karamperidou C, Caballero R et al., 2016. ENSO response to high-latitude volcanic eruptions in the Northern Hemisphere: The role of the initial conditions. Geophysical Research Letters, 43(16): 8694-8702.

Predybaylo E, Stenchikov G L, Wittenberg A T et al., 2017a. Impacts of a Pinatubo-size volcanic eruption on ENSO. Journal of Geophysical Research: Atmospheres, 122(2): 925-947.

Rampino M R, Self S, 1984. Sulphur-rich volcanic eruptions and stratospheric aerosols. Nature, 310(5979): $677-679$.

Robock A, 2000. Volcanic eruptions and climate. Reviews of Geophysics, 38(2): 191-219.

Robock A, Mao J, 1995. The volcanic signal in surface temperature observations. Journal of Climate, 8(5): 1086-1103.

Santer B D, Bonfils C, Painter J F et al., 2014. Volcanic contribution to decadal changes in tropospheric temperature. Nature Geoscience, 7(3): 185-189. 
Self S, Rampino M R, 1988. The relationship between volcanic eruptions and climate change: Still a conundrum? Eos, Transactions American Geophysical Union, 69(6): 74-86.

Self S, Rampino M R, Zhao J et al., 1997. Volcanic aerosol perturbations and strong El Niño events: No general correlation. Geophysical Research Letters, 24(10): 1247-1250.

Sheng Z, Xie S Q, Pan C Y, 2008. Probability Theory and Mathematical Statistics Course. 4th ed. Beijing: Higher Education Press. (in Chinese)

Siebert L, Simkin T, Kimberly P, 2011. Volcanoes of the World. 3rd ed. London: University of California Press.

Sigl M, Winstrup M, McConnell J R et al., 2015. Timing and climate forcing of volcanic eruptions for the past 2,500 years. Nature, 523(7562): 543-549.

Stenchikov G, Delworth T L, Ramaswamy V et al., 2009. Volcanic signals in oceans. Journal of Geophysical Research: Atmospheres, 114(D16): D16014. doi: 10.1029/2008JD011673.

Stenchikov G, Hamilton K, Robock A et al., 2004. Arctic oscillation response to the 1991 Pinatubo eruption in the SKYHI general circulation model with a realistic quasi-biennial oscillation. Journal of Geophysical Research: Atmospheres, 109(D3): D03112. doi: 10.1029/2003JD003699.

Stevenson S, Otto-Bliesner B, Fasullo J et al., 2016. "El Niño like" hydroclimate responses to last millennium volcanic eruptions. Journal of Climate, 29(8): 2907-2921.

Stommel H, Stommel E, 2010. The year without a summer. Nature Geoscience, 77(9): 2077-2094.

Taylor B L, Gal-Chen T, Schneider S H, 1980. Volcanic eruptions and long-term temperature records: An empirical search for cause and effect. Quarterly Journal of the Royal Meteorological Society, 106(447): $175-199$.

Thompson D W J, Wallace J M, Jones P D et al., 2009. Identifying signatures of natural climate variability in time series of global-mean surface temperature: Methodology and insights. Journal of Climate, 22: 6120-6141.

Timmreck C, 2012. Modeling the climatic effects of large explosive volcanic eruptions. Wiley Interdisciplinary Reviews: Climate Change, 3(6): 545-564.

Trenberth K E, Jones P D, Ambenje P et al., 2007. Observations: Surface and atmospheric climate change. In: Solomon S et al. (eds.). Climate Change 2007: The Physical Science Basis. Cambridge and New York: Cambridge University Press, 235-336.

Vicente-Serrano S M, Aguilar E, Martínez R et al., 2017. The complex influence of ENSO on droughts in Ecuador. Climate Dynamics, 48(1/2): 405-427.

Wang C, Deser C, Yu J Y et al., 2012. El Niño and southern oscillation (ENSO): A review. Coral Reefs of the Eastern Pacific, 8: 3-19.

Wang T, Guo D, Gao Y et al., 2018. Modulation of ENSO evolution by strong tropical volcanic eruptions. Climate Dynamics, 51(7/8): 2433-2453.

Yamamoto R, Iwashima T, Hoshiai M, 1975. Change of the surface air temperature averaged over the Northern Hemisphere and large volcanic eruptions during the year 1951-1972. Journal of the Meteorological Society of Japan. Ser. II, 53(6): 482-486.

Zebiak S E, Orlove B, Muñoz Á G et al., 2015. Investigating El Niño-Southern Oscillation and society relationships. Wiley Interdisciplinary Reviews: Climate Change, 6(1): 17-34.

Zhang D, Blender R, Fraedrich K, 2013. Volcanoes and ENSO in millennium simulations: Global impacts and regional reconstructions in East Asia. Theoretical and Applied Climatology, 111(3/4): 437-454.

Zhang F G, Zhang X G, 1994. The relation between large volcanic eruption in the world and the drought/flood in summer in China. Journal of Natural Disasters, 3: 40-46. 